\title{
Scaling law of average failure rate and steady-state rate in rocks
}

\author{
Shengwang Hao, ${ }^{1,2}$ Chao Liu, ${ }^{1}$ Yingchong Wang, ${ }^{1}$ and Fuqing Chang ${ }^{1}$
}

\begin{abstract}
The evolution properties in the steady stage of a rock specimen are reflective of the damage or weakening growth within and thus are used to determine whether an unstable transition occurs. In this paper, we report the experimental results for rock (granite and marble) specimens tested at room temperature and room humidity under three typical loading modes: quasi-static monotonic loading, brittle creep, and brittle creep relaxation. Deformed rock specimens in current experiments exhibit an apparent steady stage characterized by a nearly constant evolution rate, which dominates the lifetime of the rock specimens. The average failure rate presents a common power-law relationship with the evolution rate in the steady stage, although the exponent is different for different loading modes. The results indicate that a lower ratio of the slope of the secondary stage with respect to the average rate of the entire lifetime implies a more brittle failure.
\end{abstract}

Key words: Steady stage, time-to-failure, failure mode, rock.

\section{Introduction}

When a rock specimen is loaded quasi-statically in the laboratory, the accelerating deformation that leads to eventual failure always follows an apparent, constant strain rate stage. This stage is called the steady, or secondary stage, and can be observed in three types of experiments: monotonic loading by controlling the crosshead of the testing machine moving at a constant velocity (Hao et al. 2013), brittle creep testing (Brantut et al. 2014), and creep relaxation testing (Hao et al. 2014). Creep failure in rocks is typically classified within three temporal stages: primary creep, secondary creep, and accelerating tertiary creep (Scholz 1968; Okubo et al. 1991; Lockner 1993). The primary and tertiary stages

\footnotetext{
1 School of Civil Engineering and Mechanics, Yanshan University, Qinhuangdao, China. E-mail: hsw@ysu.edu.cn

2 The State Key Laboratory of Nonlinear Mechanics, Institute of Mechanics, Chinese Academy of Science, Beijing, China.
}

receive the most attention because researchers believe they are more closely associated with failure. At the primary creep stage, the strain rate $\dot{\varepsilon}(t)$ decays as a power law $\dot{\varepsilon}(t) \sim t^{-p_{c}}$, called the Andrade's law (Andrade 1910), with time following the application of the stress. The exponent $p_{c} \approx 2 / 3$ (Andrade 1910). The power law decaying behavior for the rate of damage events (Amitrano and Helmstetter 2006) in the primary stage is similar to the modified Omori's law (Omori 1894; Utsu 1961) $\dot{n}(t) \sim(c+t)^{-p_{n}}$, which describes the rate $\dot{n}(t)$ of earthquakes decaying with time after the main shock. The exponent $p_{\mathrm{n}}$ could differ from 1, though it is usually almost equal to 1 . These relations could suggest a clue for understanding and predicting the delayed failure triggered by the main shock or other causes.

The tertiary creep stage represents rapid, unstable growth, and thus it should provide insight into the failure process. Power-law creep acceleration behavior during tertiary creep was revealed by researchers (Voight 1988, 1989; Guarino et al. 2002; Nechad et al. 2005). Voight's relation (Voight 1988, 1989) $\dot{\Omega}^{-\theta} \ddot{\Omega}-A=0$ has been widely accepted as the predominant method for describing the behavior of a material in the terminal stage of failure, where $A$ and $\theta$ are the constants of experience and $\Omega$ is a measurable quantity such as strain. The dot refers to differentiation with respect to time. Similar powerlaw accelerations were also observed for natural structures, such as landslides (Saito and Uezawa 1961; Saito 1969; Petley et al. 2002), volcanoes (Voight 1988), or cliff collapses (Amitrano et al. 2005). Kilburn (2012) proposed a model to extend analyses to deformation under increasing stress and suggested an alternative relation between fracturing and stress. Hao et al. (2013) compressed granites and marbles in the laboratory by controlling the crosshead of the testing machine moving at a constant velocity. 
They defined a response function as the change of the sample's deformation with respect to the displacement of crosshead. The results showed that following a pseudo-steady stage, the response function increased rapidly as a power law relationship with displacement. Hao et al. (2016) presented a systematical analysis of this critical accelerating behavior and suggested a new relation $\dot{\Omega}^{-1} \ddot{\Omega} \sim\left(t_{f}-t\right)$ to predict failure. where $t_{f}$ represents the failure time. Efforts on describing the primary and tertiary stages improved our knowledge on the mechanism of failure and its prediction. The results also imply that the secondary stage as a stable stage between the primary and tertiary stages should reflect the specific properties of a specimen and its lifetime. Especially, the secondary stage reflects how a sample evolves from the decelerating stage to the accelerating stage.

It should be noted that damage, or weakening growth, in the secondary stage determines the unstable transition to the accelerating tertiary stage, and thus its evolution properties should contain information linked to the time to failure. In the laboratory tests, the secondary stage always dominates the lifetime of rock samples. Likewise in earthquake cycles, it is stated that throughout the interseismic period, the secondary stage is the dominant process (Perfettini and Avouac 2004). The slow speed of preearthquake deformation and strain accumulation (Chen et al. 2000; Shen et al. 2005; Meade 2007; Zhang 2013) in the Longmen Shan fault zone, which hosted the 2008 Wenchuan Mw 7.9 earthquake, China, led to an incorrect assessment of this hazard event. Therefore, revealing the relationship between the secondary stage and ultimate failure is critical to predicting failure and understanding the underlying mechanisms for it.

The strain rate in secondary stage creep is strongly dependent on the applied stress (Amitrano and Helmstetter 2006). It was shown that the time to failure for a rock decreases with increasing mean stress (Scholz 1968; Kranz et al. 1982; Boukharov et al. 1995; Baud and Meredith 1997; Lockner 1998), and that the average time to failure and the applied stress exhibits an exponential relationship (Das and Scholz 1981). The experiments (Hao et al. $2013,2014)$ indicated that the monotonic and creeprelaxation experiments also showed a pseudo-steady stage similar to the creep experiments. The dependence of the secondary creep rate and time to failure on the applied stress suggests that there should be a possible relationship between the secondary creep stage and the time to failure (Hao et al. 2014).

In this paper, we aim to establish an empirical relationship between the eventual failure and the evolution properties in the secondary stage in a rock sample under quasi-static tests. Monotonic (quasistatic constant displacement rate), brittle creep, and brittle creep relaxation experiments are the three typical laboratory experiments performed to investigate the dependency of the time-to-failure and failure modes on the secondary stage property.

\section{Experimental methodology and material}

Granite and marble, of the two major types of rocks found in the earth's crust, are tested in this experiment. Some of the physical properties of these two types of rocks are listed in Table 1 . The rocks were sampled from a depth of $\sim 10 \mathrm{~m}$ from Beijing, China, and cut into prismatic blocks $(40 \mathrm{~mm}$ in height and $16 \mathrm{~mm} \times 20 \mathrm{~mm}$ in cross-section). The surfaces of the specimens were cut for parallelism and perpendicularity between the faces, with particular emphasis on ensuring that the two ends were exactly perpendicular to the longitudinal axis of the sample. The specimens were intact, but had many randomly distributed intrinsic and natural microfractures. Figure 1 shows two microscopic images of crack pattern measured by SEM (scanning electron microscope) for two investigated rocks under loading to give an insight into their microstructures and fracture behaviors.

We performed three types of quasi-static experiments that were designed to simulate the three typical types of fault loading occurring in the upper crust. Figure 2 illustrates the experimental set-up and loading processes: monotonic loading (type 1), brittle creep (Amitrano and Helmstetter 2006; Heap et al. 2011; Brantut et al. 2013, 2014) (type 2), and brittle creep relaxation (Hao et al. 2013) (type 3). In laboratory tests, the loading system consists of a load apparatus and a deformed sample. The load apparatus is always modeled by an analogous "elastic spring" 
Table 1

Physical properties of rocks

\begin{tabular}{lllllll}
\hline Rocks & $\begin{array}{l}\text { Bulk density }(\mathrm{g} / \\
\left.\mathrm{cm}^{3}\right)\end{array}$ & $\begin{array}{l}\text { Water absorption } \\
(\%)\end{array}$ & $\begin{array}{l}\text { Uniaxial compressive strength } \\
\text { (Mpa) }\end{array}$ & $\begin{array}{l}\text { Type 1 } \\
\text { experiments }\end{array}$ & $\begin{array}{l}\text { Type 2 } \\
\text { experiments }\end{array}$ & $\begin{array}{l}\text { Type 3 } \\
\text { experiments }\end{array}$ \\
\hline Granite & $\sim 2.5$ to 2.7 & 0.16 & 222.5 & $\boldsymbol{V}$ & $\boldsymbol{V}$ \\
Marble & $\sim 2.6$ to 2.8 & 0.46 & 162.4 & $\boldsymbol{V}$ & - & $\checkmark$ \\
\hline
\end{tabular}

Water absorption is the mass's ratio of water absorbed in the atmosphere by unit volume rock with respect to the mass of the dry rock

(a)

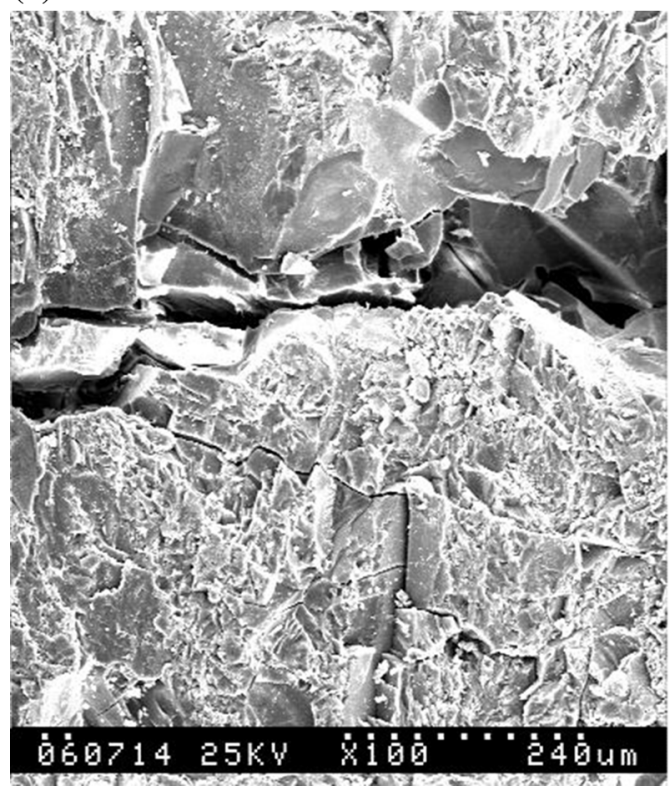

(b)

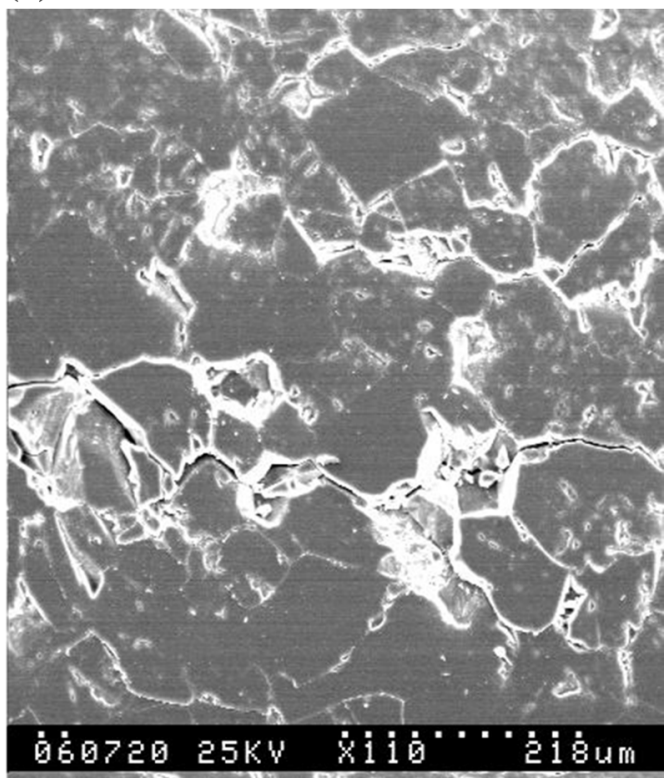

Figure 1

SEM images of crack patterns under loading for a granite. b Marble

as shown in Fig. 2. The displacement, $U$, of the crosshead of the testing machine includes the deformations of the loading apparatus, and that, $u$ of the rock samples. In the first type of experiment (type 1), a rock specimen is compressed by monotonically and quasi-statically moving the crosshead of the testing machine at a constant rate (i.e. $U$ is in linear relation with time). Brittle creep experiments (Amitrano and Helmstetter 2006; Heap et al. 2011; Brantut et al. 2013, 2014) were the second type of experiment (type 2) performed. In these experiments, a rock specimen was first loaded to a prescribed initial stress, which was then maintained at a constant value to observe the evolution of the deformation. The evolution of the deformation relates to the responses under applied and invariant stresses, (Benioff 1951; Scholz 1968; Singh 1975; Lockner 1993; Du and McMeeking 1995; Lienkaemper et al. 1997; Heap et al. 2011) and could be possibly analogous to some processes of fault weakening that may lead to a seismic rupture. Brittle creep relaxation (Hao et al. 2014) was the third type of experiment (type 3) performed. In this experiment, a rock specimen was first loaded to an initial state by imposing an initial displacement to the crosshead of the testing machine. Then, the displacement was held at a constant value. The rock specimen then undergoes a combination process in which it deforms but the stress relaxes because the crosshead of the testing machine is held constant. This experiment simulated the process in which the 
(a)

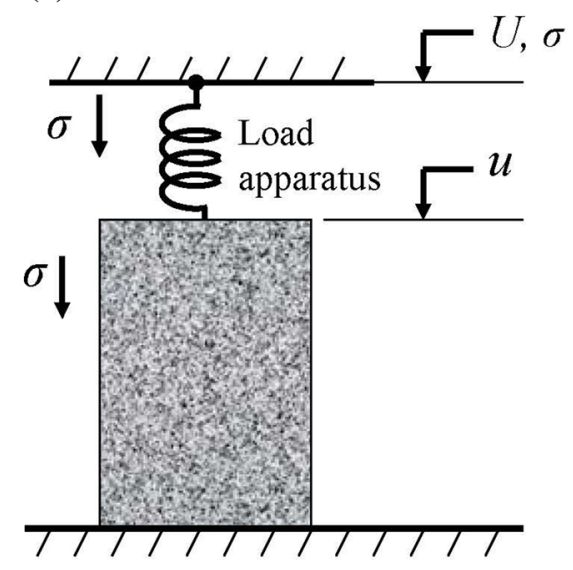

$U$ : Measured by LVDT

$u$ : Measured by extensometers

$\sigma$ : Measure by force sensor

$k$ : Stiffness of load apparatus

$t$ : Time (b)

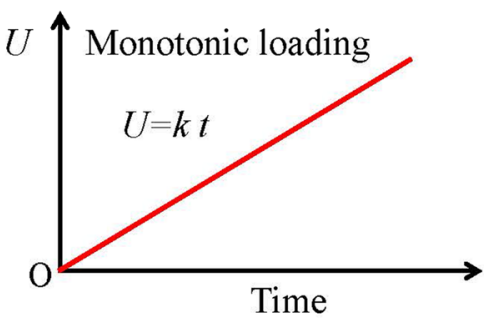

(c)

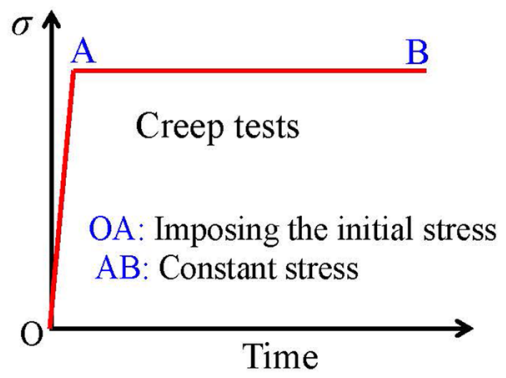

(d)

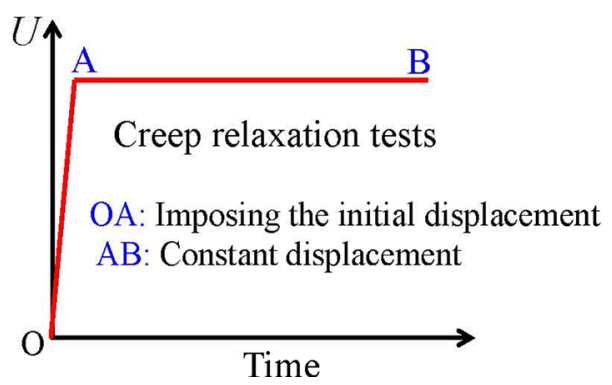

Figure 2

Sketch of the experimental set-up and loading processes. a Sketch of the experimental set-up; $\mathbf{b}$ the monotonic loading process; $\mathbf{c}$ the brittle creep test loading process; $\mathbf{d}$ the creep relaxation test loading process

elastic energy release of the surroundings drives the damage propagation, or weakening of a fault zone after a main earthquake (Hao et al. 2014).

In the experiments, the rock specimens were compressed uniaxially along the $40-\mathrm{mm}$ axis at room temperature, ranging from 10 to $30^{\circ} \mathrm{C}$, and room humidity, with average relative humidity $\sim 62 \%$. Uniaxial compression was achieved using a screwdriven crosshead, which is a universal electromechanical testing machine equipped with a load cell with an offset load of $1 \mathrm{kN}$. The deformation, $u$, of a specimen was measured using $1 \mu \mathrm{m}$ resolution extensometers located on the sides of the specimen. The displacement, $U$, of the crosshead was continuously measured using a linear variable differential transformer with a resolution $1 \mu \mathrm{m}$.

In the type 1 experiment, the rock specimens were compressed by monotonically increasing the crosshead displacement at a rate of $0.02 \mathrm{~mm} / \mathrm{min}$ (leading to a strain rate of approximately $8.3 \times 10^{-6} \mathrm{~s}^{-1}$ ) until failure (i.e., no-hold step). The experimental protocols for type 1, type 2, and type 3 are illustrated in Figs. 3, 4 and 5. In brittle creep tests (type 2), the rock specimen was first loaded to an initial stress, ( $A B$ portion in Fig. 4) which was held at a constant value ( $\mathrm{AB}$ portion in Fig. 4) while the deformation was measured. In the brittle creep relaxation experiment (type 3 ), the rock specimen was first rapidly loaded to the initial deformation state (OA part in Fig. 5) with a crosshead speed of $1.5 \mathrm{~mm} / \mathrm{min}$ for the subsequent relaxation test. The crosshead was then held at this constant position ( $\mathrm{AB}$ portion in Fig. 5) and the deformation and stress of the sample were measured as it relaxed. Hao et al. (2014) have detailed this loading process. 


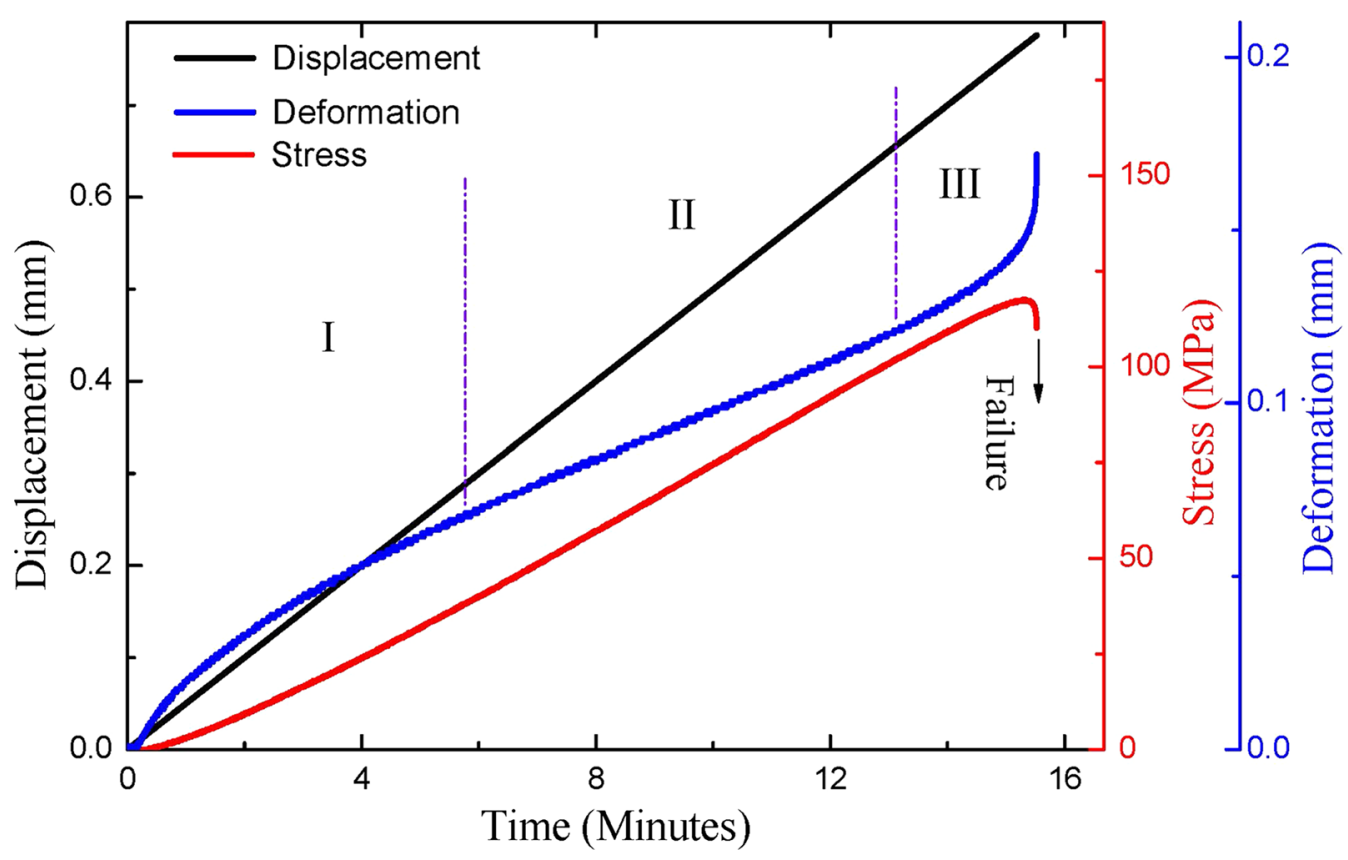

Figure 3

Deformation-time and stress-time plots from a static monotonic experiment illustrating the experimental protocol. The displacement, $U$, of the crosshead of the testing machine is controlled to increase linearly with respect to time and is a combination of the deformation of the loading apparatus and the deformed rock sample. The rock specimen failed catastrophically at the post-failure portion after the peak stress

In this paper, the symbol $t_{f}$ denotes the failure time and $t_{0}$ represents the start time of the creep phase, or creep-relaxation phase, in brittle creep or creep-relaxation experiments. Thus, $\left(t_{f}-t_{0}\right)$ is the creep time or creep-relaxation time in these two experiments. The experimental parameters of all specimens tested in three types of experiments are listed in Tables 2, 3 and 4. It should be mentioned that there was an event of fracture that occurred during the testing of specimens SC-G-80-2 and SCG-85-3. An audible sound was emitted by the fracture but the specimen did not fail completely. This small event induced a small jump in the curves (see Fig. 7a, b). Thus, the steady stage has a more direct relation with this small event than the macroscopic failure, and then we select the $u_{f}$ and $t_{f}$ corresponding to this small event to calculate the value of the average creep rate $\mu=\frac{\mu_{f}-\mu_{0}}{t_{f}-t_{0}}$.

We calculated the rate of deformation (or stress) $\mathrm{d} u / \mathrm{d} U, \mathrm{~d} \sigma / \mathrm{d} t$ or $\mathrm{d} \varepsilon / \mathrm{d} t$ by using the finite difference method. This constant rate stage is defined as the secondary stage in the present paper, and correspondingly, the value of the rate plateau is determined as the slope, $\lambda s$, of the steady stage in the deformation (or stress) curves.

\section{Results}

\subsection{Stages of evolution to failure}

Let us have a close examination of the evolution of the response variables, such as stress or deformation, in the three experiments. Figure 3 shows a typical result for rock specimens tested in the type 1 experiment. The solid blue line plots the axial deformation $(u)$ against time, and the solid red squares plot the stress-time curve. It can be seen that at the early stage, the stress-time curve is slightly convex upwards (also see Rudnicki and Rice 1975; Jeager et al. 2007; Hao et al. 2007, 2013) and the deformation growth is characterized by an initial convex upward phase of decreasing strain rate. Later, an almost linear stress-time relation, as well as a nearly linear $u \sim t$ relation, follows. Finally, the deformation, $u$, 


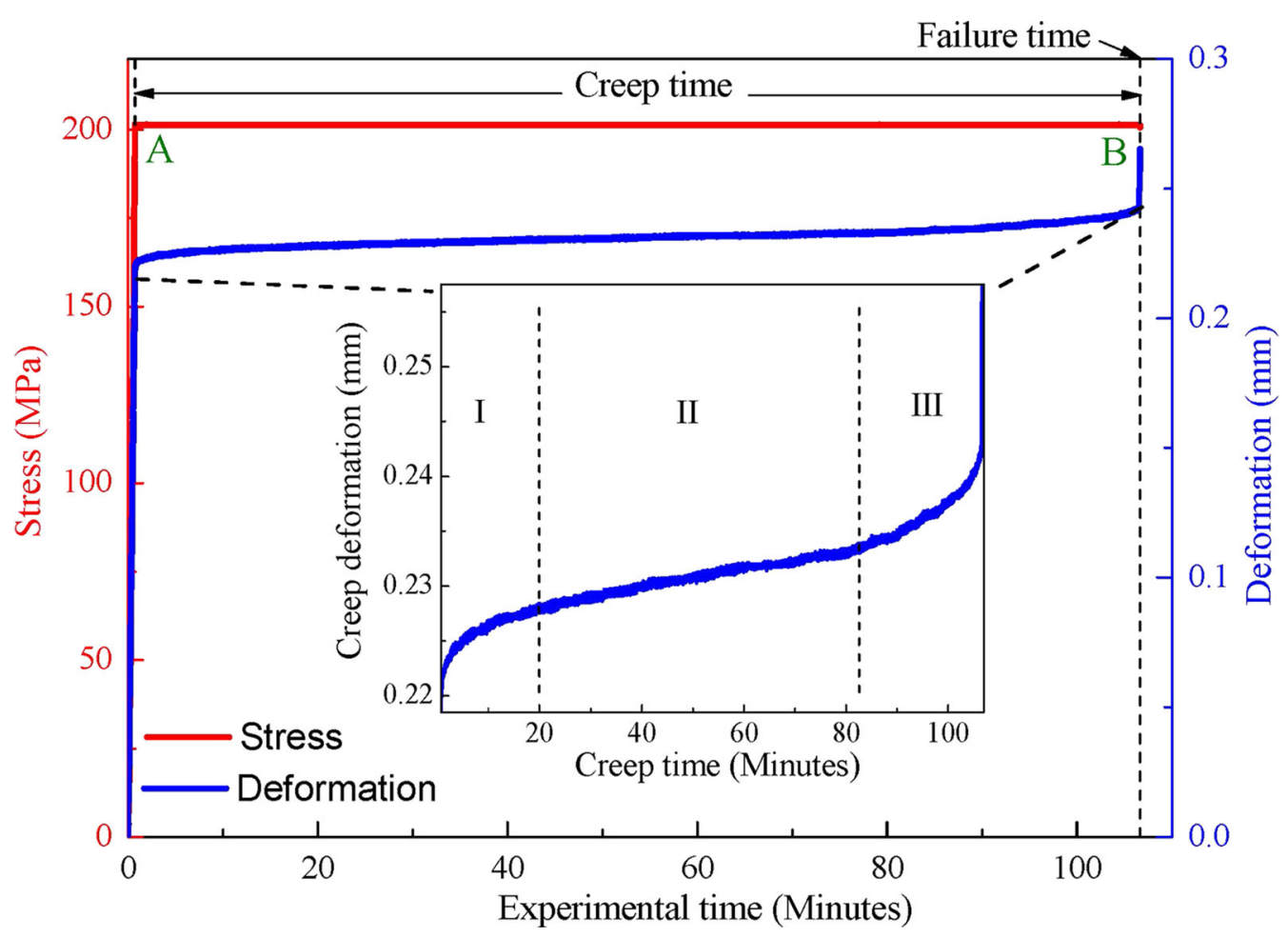

Figure 4

Stress-time and deformation-time curves in a brittle creep experiment on rocks. The experiment is divided into two phases: a phase (0A) of imposing an initial stress on rock samples, and a constant stress (creep) phase $(A B)$. The inset shows a zoomed-in view to the creep phase.

Three creep phases $(I, I I, I I I)$ are labeled on the inset and a long steady stage with almost constant creep rate is indicated

of the sample increases rapidly to catastrophic failure, which is associated with a jump of stress (Fig. 3). It has been demonstrated that the catastrophic failure is induced by the elastic energy release from the loading apparatus, which occurs at some point in the strain softening section after peak stress (Salamon 1970; Hundson et al. 1972; Labuz and Biolzi 1991; Bai et al. 2005; Jeager et al. 2007; Hao et al. 2007, 2010, 2013). Figure 6 plots the deformation-displacement curves for specimens. It shows that specimens exhibit the typical threestaged behavior of primary, secondary, and terminal accelerated evolution to failure. In the primary stage, the deformation-displacement curve is concave downward and the slope of the deformationdisplacement decreases with increasing displacement. Later, an almost linear deformationdisplacement relation, i.e. a pseudo-steady stage follows. In the tertiary stage, the curve is concaved upwards and the deformation increases rapidly.
In brittle creep tests, rock specimens were loaded with different, constant applied stresses. Figure 4 shows a typical result of the type 2 experiment to illustrate the complete process of brittle creep testing. It can be seen that at the creep phase ( $\mathrm{AB}$ portion) after imposing the initial stress (OA portion), the stress was held well at a constant value. Figure $7 \mathrm{a}-\mathrm{d}$ shows the curves of strain against time for all samples during the creep phase, and the applied stresses are indicated in the corresponding figures. It can be seen that the deformation vs. time curves show typical brittle creep behavior characterized by the three-stage behavior as seen in previous studies (Amitrano and Helmstetter 2006; Heap et al. 2011; Brantut et al. 2013, 2014). Each primary creep stage is characterized by an initially high strain rate that decreased over time to reach an almost constant secondary stage strain rate, which is often interpreted as steady creep. Finally, the samples entered a tertiary phase characterized by an accelerated increase in strain. This 


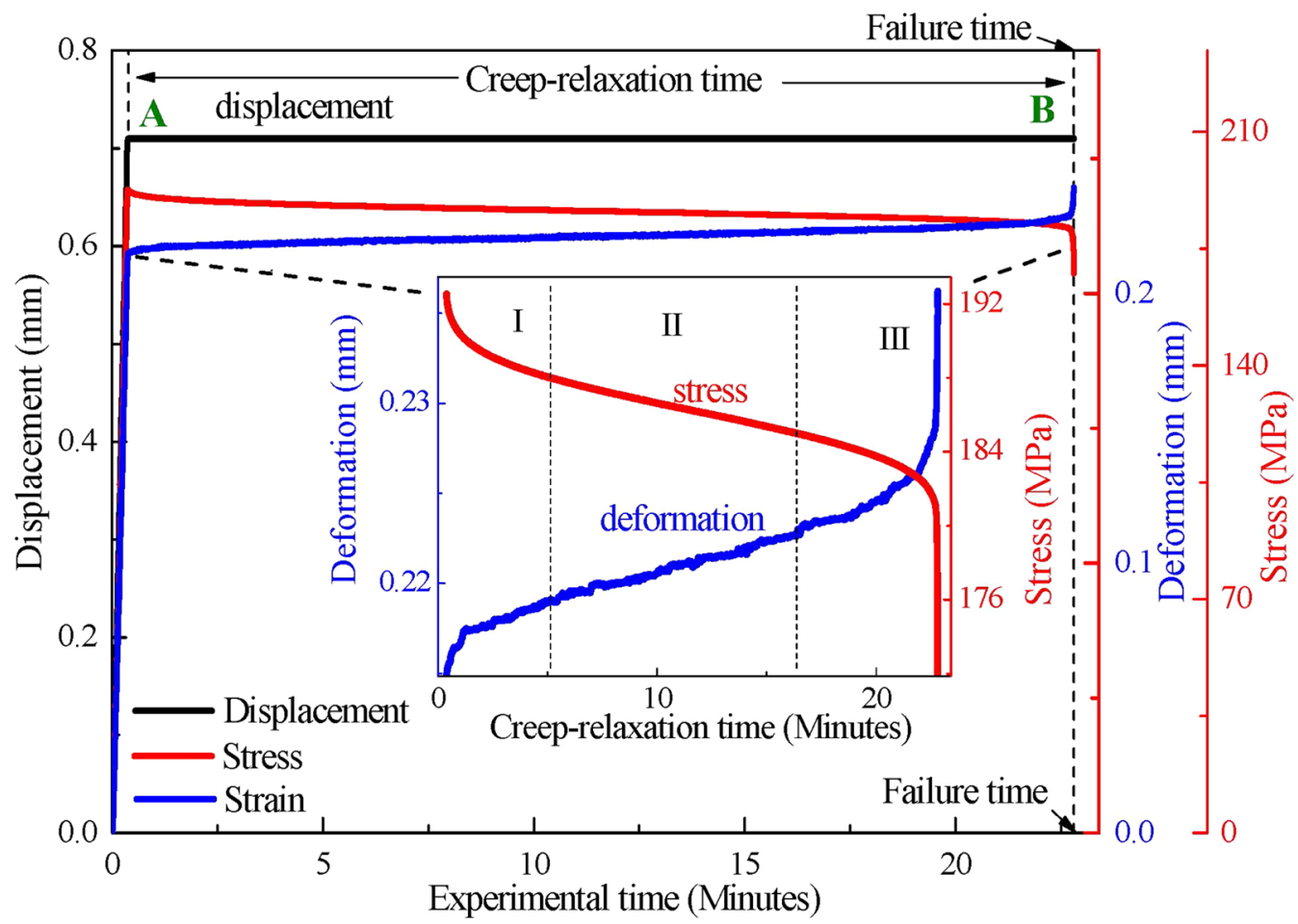

Figure 5

An example of the creep-relaxation curves observed in the experiments. The experiment is divided into two phases: a phase (0A) of applying an initial displacement on the crosshead, and a constant displacement (creep-relaxation) phase $(A B)$. The inset shows a zoomed-in view of the creep-relaxation phase. Three phases $(I, I I, I I I)$ are labeled on the inset and a long steady stage with a nearly constant creep-relaxation rate is indicated

eventually resulted in macroscopic failure of the rock specimen.

Figure 5 illustrates a typical brittle creep relaxation result to demonstrate the complete process. As shown, the displacement was held constant (AB portion) well after the crosshead had reached the initial position (OA portion) (Fig. 5). The evolution curves of the deformation and stress at the constant displacement $(\mathrm{AB})$ portion shown in the inset indicate that stress relaxation accompanied the increase in the deformation of the specimen. Figure 8 shows the results at the creep relaxation phase. It is clear that a typical stress relaxation process can be described as the rapid initial relaxation of stress, followed by a pseudo-steady stage in which the stress decreases at constant rate (Hao et al. 2014). This constant rate of stress relief terminates abruptly by an acceleration of stress loss and deformation that often culminates in catastrophic failure (Fig. 5).
In the brittle creep and creep relaxation experiments, some specimens immediately failed upon application of the initial stress or displacement. These experiments were discarded as they produced no data (the typical curves in type 2 and type 3 experiments are shown in Figs. 15 and 16 in Appendix, respectively). Some specimens did not fail during the available time window of 4 days. These experiments were also discarded (the exemplary curves in type 2 and type 3 experiments are shown in Figs. 15 and 16, respectively).

\subsection{Scaling law of average failure rate and steady- state rate}

It can be seen that the monotonic and creeprelaxation experiments showed a pseudo-steady stage similar with the creep experiments. To further characterize the three stages of the evolution of the 
Table 2

Experimental conditions and results for all type 1 experiments

\begin{tabular}{|c|c|c|c|c|c|c|c|c|c|}
\hline Sample number & $\sigma_{\max }(\mathrm{MPa})$ & $\sigma_{\mathrm{f}}(\mathrm{MPa})$ & $u_{f}(\mathrm{~mm})$ & $U_{f}(\mathrm{~mm})$ & Sample number & $\sigma_{\max }(\mathrm{MPa})$ & $\sigma_{\mathrm{f}}(\mathrm{MPa})$ & $u_{f}(\mathrm{~mm})$ & $U_{f}(\mathrm{~mm})$ \\
\hline Tl-M-1 & 189.2 & 189.0 & 0.221 & 0.550 & Tl-G-1 & 77.76 & 77.89 & 0.271 & 0.596 \\
\hline Tl-M-2 & 183.7 & 182.6 & 0.262 & 0.573 & Tl-G-2 & 58.45 & 58.73 & 0.258 & 0.548 \\
\hline Tl-M-3 & 180.9 & 179.3 & 0.272 & 0.570 & Tl-G-3 & 69.79 & 69.97 & 0.243 & 0.585 \\
\hline Tl-M-4 & 182.5 & 180.1 & 0.272 & 0.560 & Tl-G-4 & 59.85 & 60.10 & 0.252 & 0.563 \\
\hline Tl-M-5 & 110.4 & 108.6 & 0.220 & 0.397 & Tl-G-5 & 39.179 & 40.146 & 0.328 & 0.423 \\
\hline Tl-M-6 & 127.6 & 126.4 & 0.205 & 0.397 & Tl-G-6 & 61 & 61.40 & 0.304 & 0.610 \\
\hline Tl-M-7 & 125.6 & 124.4 & 0.241 & 0.396 & Tl-G-7 & 61.88 & 61.98 & 0.228 & 0.542 \\
\hline Tl-M-8 & 113.3 & 112.4 & 0.260 & 0.407 & Tl-G-8 & 42.46 & 42.63 & 0.216 & 0.431 \\
\hline Tl-M-9 & 133.5 & 132.5 & 0.211 & 0.398 & Tl-G-9 & 49.05 & 49.46 & 0.311 & 0.526 \\
\hline Tl-M-10 & 111.5 & 110.1 & 0.236 & 0.375 & Tl-G-10 & 41.19 & 41.76 & 0.303 & 0.502 \\
\hline Tl-M-11 & 122.7 & 121.4 & 0.233 & 0.384 & Tl-G-11 & 46.61 & 47.77 & 0.292 & 0.509 \\
\hline Tl-M-12 & 174.5 & 173.2 & 0.335 & 0.542 & Tl-G-12 & 62.96 & 63.36 & 0.213 & 0.515 \\
\hline Tl-M-13 & 121.0 & 119.9 & 0.216 & 0.386 & Tl-G-13 & 68.54 & 68.7 & 0.206 & 0.559 \\
\hline Tl-M-14 & 196.1 & 196.1 & 0.240 & 0.582 & Tl-G-14 & 71.69 & 71.96 & 0.233 & 0.581 \\
\hline Tl-M-15 & 174.4 & 174.4 & 0.186 & 0.481 & Tl-G-15 & 74.51 & 74.91 & 0.277 & 0.583 \\
\hline Tl-M-16 & 172.6 & 172.5 & 0.183 & 0.466 & & & & & \\
\hline Tl-M-17 & 88.8 & 87.9 & 0.289 & 0.395 & & & & & \\
\hline Tl-M-18 & 91.3 & 90.8 & 0.287 & 0.395 & & & & & \\
\hline Tl-M-19 & 182.4 & 181.3 & 0.298 & 0.584 & & & & & \\
\hline
\end{tabular}

$T 1$ type 1 experiments, $M$ marble, $G$ granite. Load rate: $\mathrm{d} U / \mathrm{d} t=0.02 \mathrm{~mm} / \mathrm{min}$

properties of rock failure, the first derivatives of the deformation with respect to the displacement $(\mathrm{d} u / \mathrm{d} U)$ for the monotonic experiments were plotted and two such plots are shown in Fig. 9 as examples. For the brittle creep experiments, the first derivatives of the deformation-time curves (i.e., the strain rate against time) are calculated and shown in Fig. 10. Figure 11 presents the curves of the strain and stress rates against time for the creep relaxation tests.

It can be seen that the responses showed a common three-stage behavior for all three experiments. All of these plots demonstrated that there are long segments with an almost constant slope, as indicated by the horizontal sections of the curves. It is clear that the secondary stage dominated the lifetime of the specimens in all experiments under the three loading modes. The evolution characteristics of the secondary stage determine the transition from the steady state to the unstable state in the tertiary stage and thus determine whether macroscopic failure will occur.

For the brittle creep relaxation experiments and creep experiments, the resultant creep deformation is given by $u_{f}-u_{0}$, and hence, $\mu=\frac{\mu_{f}-\mu_{0}}{t_{f}-t_{0}}$ represents the average creep deformation rate. Similarly, for the monotonic loading experiments, the average deformation rate is $\mu=\frac{\mu_{f}}{U_{f}}$. Here, $\mu_{f}$ is the resultant deformation and $\mu_{f}$ is the resultant loading displacement (or a proxy measure of lifetime because $U$ has a linear relationship with time). For a brittle rock material, the initiation, propagation, interaction, and coalescence of cracks are the main mechanism of deformation. Therefore, the deformation can be a proxy measurement of the change in damage during sample deformation. The ratio $\lambda_{s} / \mu$ represents proportion of damage rate in the secondary state. A larger value of $\lambda_{s} / \mu$ implies a smaller proportion of duration in the secondary stage, and consequently, a larger part of the damage is developed in the tertiary stage.

Therefore, as shown in Figs. 6, 7 and 8, a steep slope of the steady stage implies a short lifetime. The double-logarithm plots of the lifetime and $\lambda_{s}$, are shown in Figs. 12, 13 and 14. The linear relationship in the double-logarithm plots indicates that $\mu$ follows a power law

$$
\mu=A \lambda_{s}^{\alpha}
$$

with the secondary creep rate $\lambda_{s}$. 
Table 3

Experimental conditions and results for all type 2 experiments

\begin{tabular}{|c|c|c|c|c|}
\hline Sample number & $\sigma_{\max }(\mathrm{MPa})$ & $u_{0}(\mathrm{~mm})$ & $u_{\mathrm{f}}(\mathrm{mm})$ & $t_{f}-t_{f}(\mathrm{~s})$ \\
\hline T2-G-80-1 & 181.2 & 0.208 & 0.262 & 570 \\
\hline T2-G-80-2 & 181.2 & 0.216 & 0.267 & 6355 \\
\hline T2-G-80-3 & 181.2 & 0.208 & 0.232 & 5775 \\
\hline T2-G-85-1 & 190.6 & 0.227 & 0.265 & 133 \\
\hline T2-G-85-2 & 190.6 & 0.226 & 0.255 & 397 \\
\hline T2-G-85-3 & 190.6 & 0.216 & 0.227 & 2051 \\
\hline T2-G-90-1 & 203.1 & 0.247 & 0.271 & 56 \\
\hline T2-G-90-2 & 203.1 & 0.222 & 0.248 & 19 \\
\hline T2-G-90-3 & 203.1 & 0.237 & 0.269 & 115 \\
\hline T2-G-9(M & 203.1 & 0.239 & 0.267 & 122 \\
\hline T2-G-90-5 & 203.1 & 0.228 & 0.252 & 290 \\
\hline T2-G-90-6 & 203.1 & 0.231 & 0.262 & 539 \\
\hline T2-G-90-7 & 203.1 & 0.232 & 0.254 & 830 \\
\hline T2-G-90-8 & 203.1 & 0.227 & 0.252 & 9929 \\
\hline T2-G-90-9 & 203.1 & 0.227 & 0.245 & 1317 \\
\hline T2-G-90-10 & 203.1 & 0.232 & 0.250 & 378 \\
\hline T2-G-90-11 & 203.1 & 0.224 & 0.257 & 4569 \\
\hline T2-G-90-12 & 203.1 & 0.232 & 0.253 & 481 \\
\hline T2-G-95-1 & 212.5 & 0.293 & 0.321 & 23 \\
\hline T2-G-95-2 & 212.5 & 0.289 & 0.310 & 20 \\
\hline T2-G-95-3 & 212.5 & 0.251 & 0.276 & 32 \\
\hline T2-G-95-4 & 212.5 & 0.250 & 0.279 & 153 \\
\hline T2-G-95-5 & 212.5 & 0.244 & 0.266 & 230 \\
\hline T2-G-95-6 & 212.5 & 0.236 & 0.269 & 559 \\
\hline
\end{tabular}

It should be mentioned that there was an event of fracture that occurred during the testing of specimens SC-G-80-2 and SC-G-85-3. We heard a sound emitted by the fracture but the specimen did not fail completely. This small event induced a small jump in the curves (see Fig. 7a, b). Thus, the stable stage has a more direct relation with this small event than the macroscopic failure, and then we select the $u_{f}$ and $t_{f}$ corresponding to this small event to calculate the value of the average creep rate $\mu$

$T 2$ type 2 experiments, $G$ granite

Table 4

Experimental conditions and results for all type 3 experiments

\begin{tabular}{|c|c|c|c|c|c|c|}
\hline Sample number & $U(\mathrm{~mm})$ & $\sigma_{0}(\mathrm{MPa})$ & $\sigma_{\mathrm{f}}(\mathrm{MPa})$ & $u_{0}(\mathrm{MPa})$ & $u_{\mathrm{f}}(\mathrm{MPa})$ & $t_{f}-t_{f}(\mathrm{~s})$ \\
\hline T3-G-1 & 0.770 & 238.4 & 227.9 & 0.241 & 0.231 & 347 \\
\hline T3-G-2 & 0.750 & 222.2 & 237.1 & 0.214 & 0.232 & 797 \\
\hline T3-G-3 & 0.760 & 2040 & 229.1 & 0.174 & 0.193 & 497 \\
\hline T3-G-4 & 0.730 & 228.0 & 209.3 & 0.222 & 0.243 & 2471 \\
\hline T3-G-5 & 0.710 & 2140 & 193.6 & 0.214 & 0.238 & 1345 \\
\hline T3-G-6 & 0.682 & 169.7 & 120.9 & 0.107 & 0.182 & 125 \\
\hline T3-G-7 & 0.753 & 214.7 & 183.1 & 0.169 & 0.219 & 285 \\
\hline T3-G-S & 0.753 & 225.4 & 198.3 & 0.147 & 0.189 & 208 \\
\hline T3-G-9 & 0.741 & 203.1 & 170.0 & 0.220 & 0.281 & 593 \\
\hline T3-G-10 & 0.721 & 202.7 & 149.8 & 0.233 & 0.324 & 926 \\
\hline T3-M-1 & 0.760 & 225.8 & 214.8 & 0.226 & 0.237 & 593 \\
\hline T3-M-2 & 0.783 & 186.0 & 157.8 & 0.160 & 0.239 & 83 \\
\hline T3-M-3 & 0.756 & 191.9 & 152.9 & 0.543 & 0.382 & 129 \\
\hline T3-M-4 & 0.756 & 166.9 & 127.2 & 0.342 & 0.456 & 64 \\
\hline
\end{tabular}

$T 2$ type 3 experiments, $M$ marble, $G$ granite 


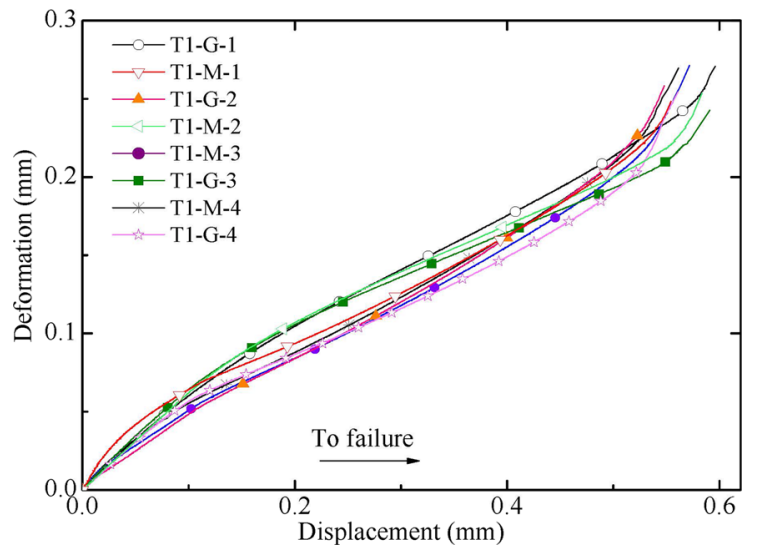

Figure 6

Deformation curves in monotonic tests. The curves exhibit the apparent tri-stage behaviors. $T 1$ type 1 experiments, $G$ granite,

$M$ marble
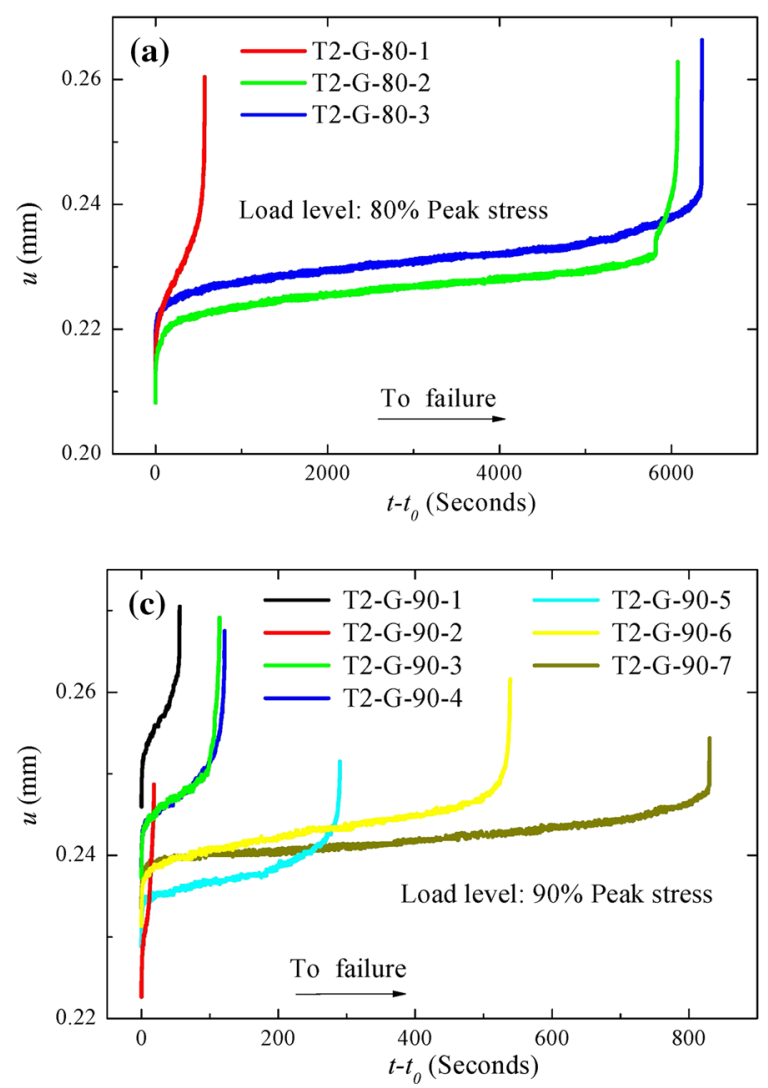

The power law exponent was approximately 0.70 $[0.72 \pm 0.04$ for the marble specimens (Fig. 12a) and $0.70 \pm 0.04$ for the granite specimens (Fig. 12b)] in the monotonic loading experiments. The exponent $\alpha$ is $0.92 \pm 0.04$ in the brittle creep experiments (Fig. 13), which is almost a linear relationship between $\mu$ and $\lambda_{s}$. On the other hand, the exponent $\alpha$ is about $0.85[0.84 \pm 0.03$ (Fig. 14a) for stress relaxation and $0.86 \pm 0.03$ (Fig. 14b) for deformation evolution] in the brittle creep relaxation experiments. Our results indicate that the power law relation (1) is fitted well for the three types of experiments.
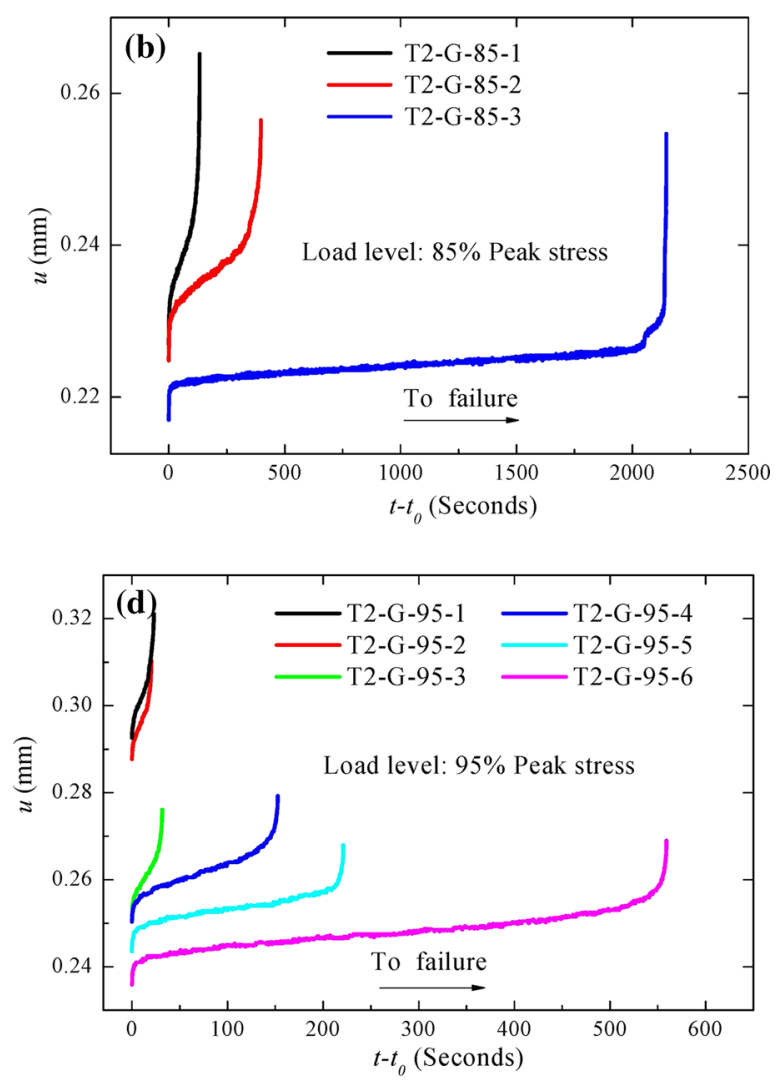

Figure 7

Creep curves for different applied stress levels. a Load level: $80 \%$ peak stress; b load level: $85 \%$ peak stress; c load level: $90 \%$ peak stress; d load level: $95 \%$ peak stress. The curves exhibit the apparent tri-stage behaviors. The specimens present different failure times and strain under the same stress level. $T 2$ type 2 experiments, $G$ granite, $M$ marble 

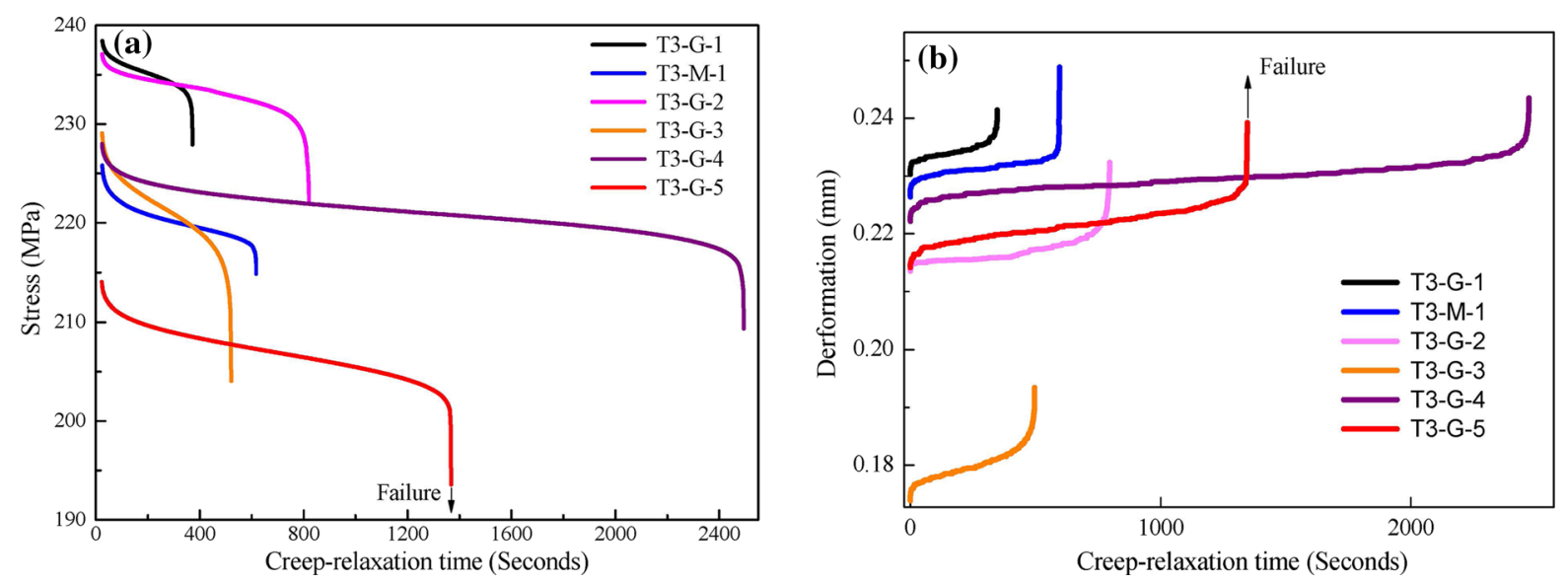

Figure 8

Creep-relaxation curves for six rock samples. Temporal evolution of $\mathbf{a}$ the stress and $\mathbf{b}$ deformation. The curves exhibit the apparent tri-stage behaviors. T3 type 3 experiments, $G$ granite, $M$ marble

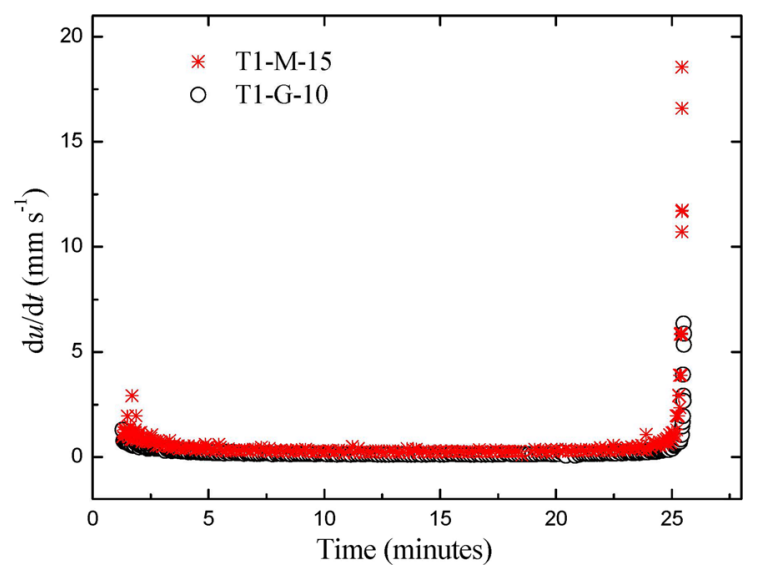

Figure 9

Deformation rate-displacement curves in the monotonic test. $G$ granite, $M$ marble

\section{Discussion}

The subcritical growth of micro cracks, i.e. crack growth, can occur when the stress intensity factor $K$ is lower than its critical value (also called as facture toughness). $K_{c}$, is suggested to be the main mechanism responsible for brittle creep of rocks (Scholz 1972; Atkinson and Meredith 1987; Lockner 1993; Amitrano and Helmstetter 2006). Subcritical crack growth can be caused by several competing mechanisms, including: stress corrosion, diffusion, dissolution, ion exchange and microplasticity (Atkinson 1984; Atkinson and Meredith 1987). The

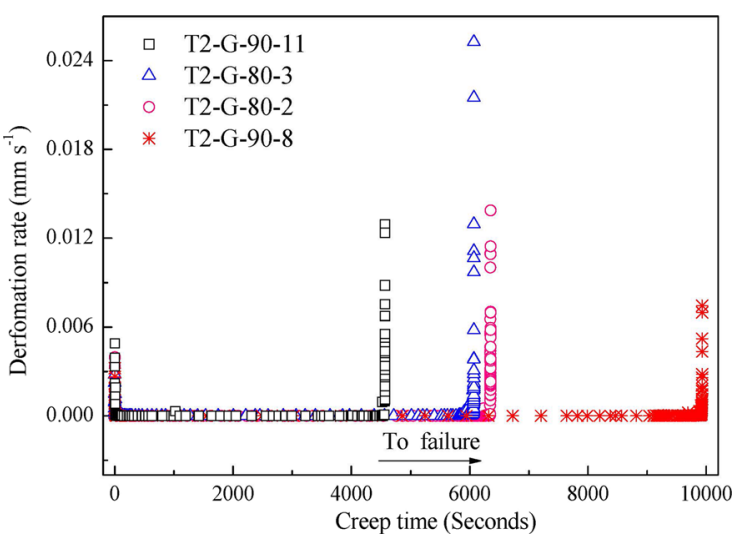

Figure 10

Deformation rate-time curves in the brittle creep experiments. $G$ granite

theory of stress corrosion postulates that the reaction between strained bonds and the environmental agent produces a weakened (an activated) state that can then be broken at lower stresses than the unweakened bonds. The model of diffusion assumes that mass transport can be the dominant mechanism of subcritical crack growth. The dissolution model suggests that the growth rate of cracks is controlled by the silica dissolution rate. According to the theory of ion exchange, if the chemical environment contains species which can undergo ion exchange with species in the solid phase and if there is a gross mismatch in the size of these different species, then lattice strain can result from ion exchange which can facilitate 


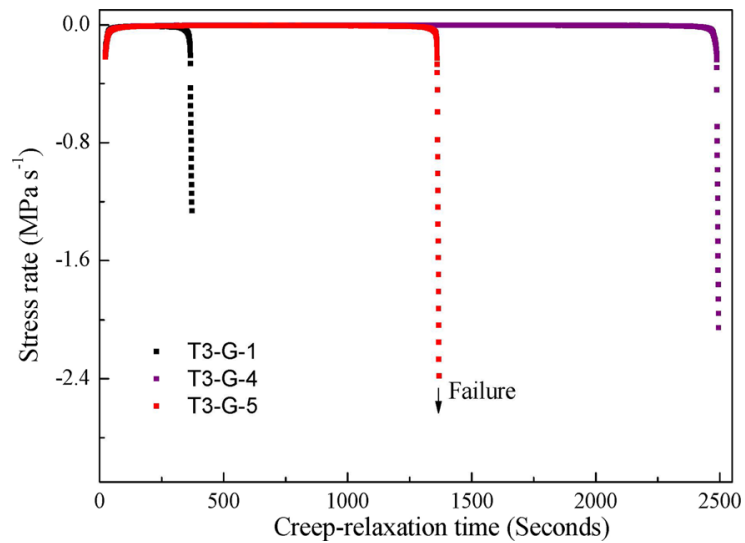

Figure 11

Stress rate-time curves in the creep-relaxation experiments. $G$ granite

crack growth. The theory of micro-plasticity suggests that the dislocation activity allowing plastic flow may be a significant mechanism of crack propagation. It is assumed that stress corrosion is the main mechanism of subcritical growth in shallow crustal conditions (Atkinson 1984; Atkinson and Meredith 1987).

The crack velocity fits a power law with stress intensity factor (Charles 1958; Atkinson 1984; Atkinson and Meredith 1987; Amitrano and Helmstetter 2006)

$$
\frac{V}{V_{0}}=\left(\frac{K}{K_{c}}\right)^{q} \exp \left(\frac{-H}{R T}\right) \quad K_{0}<K<K_{\mathrm{c}}
$$

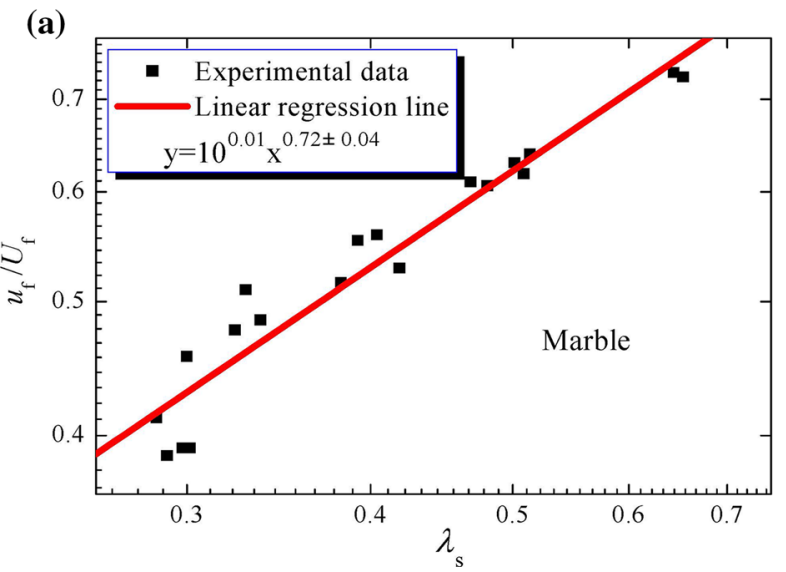

where $V$ is the crack growth velocity, $R$ is the gas constant, $T$ is the temperature, $H$ is the activation energy, and $K_{0}$ is the threshold value below which no crack propagation is observed. Based on Eq. (2), a power-law relationship of the time-to-failure with the applied stress (Charles 1958; Cruden 1974; Kranz 1980; Lockner 1993; Amitrano and Helmstetter 2006) has been derived analytically and observed experimentally

$$
t_{f}=t_{*}\left(\frac{\sigma}{\sigma_{*}}\right)^{-p}
$$

The constants $t_{*}$ and $\sigma_{*}$ depend on rock properties and ambient conditions (Scholz 1972). An exponential relation (Wiederhorn and Bolz 1970; Das and Scholz 1981; Amitrano and Helmstetter 2006)

$$
t_{f}=t_{*} \exp \left(-b \frac{\sigma}{\sigma_{*}}\right)
$$

has also been suggested. These two empirical relations (3) and (4) are equivalent in terms of correlation coefficient (Amitrano and Helmstetter 2006) and indicate the stress dependence of the time-to-failure.

A theoretical derivation presented by Main (2000) gives a relationship between the strain rate $\dot{\varepsilon}$ and stress

$$
\dot{\varepsilon}=C \sigma^{m},
$$

where $C$ is a constant. Then, Eqs. (3) and (5) suggest a possible power law relation

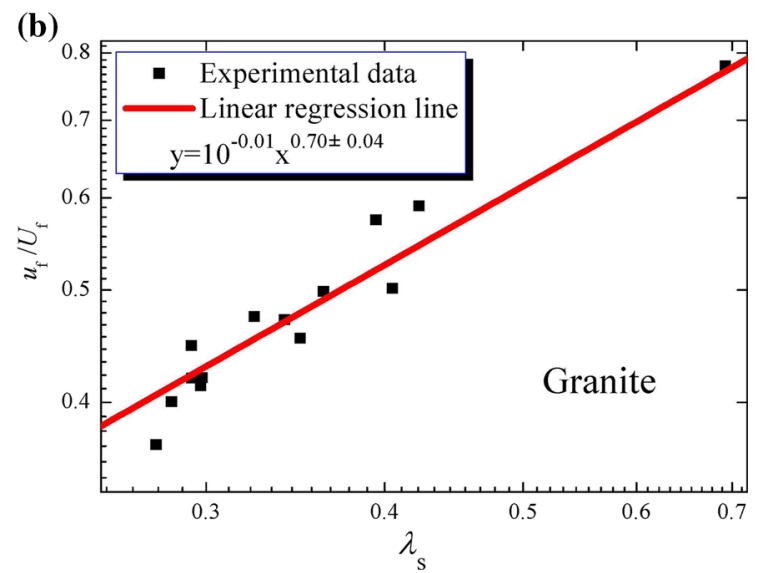

Figure 12

Double-logarithm plots of $\mu$ and $\lambda s$ in the monotonic loading tests. a Marble, $\mathbf{b}$ granite. The data fit well a power law. The two types of rock exhibit few differences with the exponents: marble is 0.72 and granite is 0.70 


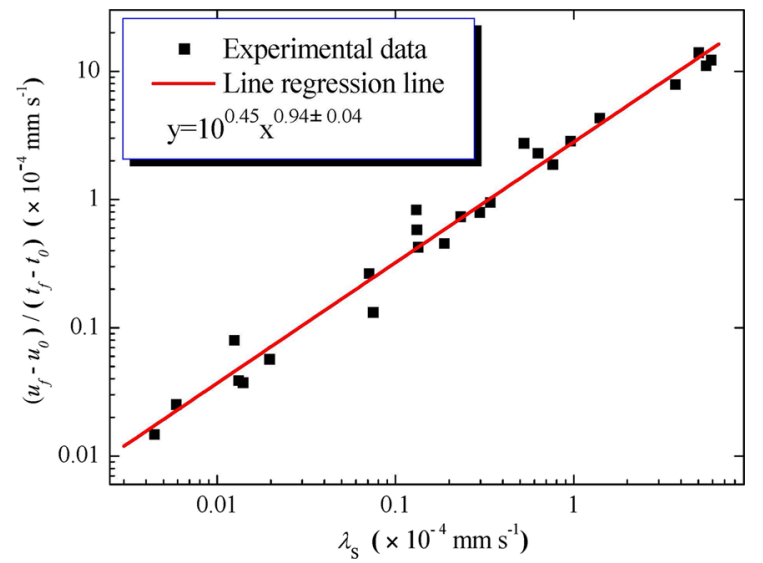

Figure 13

The double-logarithm plots of $\mu$ and $\lambda s$ in brittle creep tests. The data fit well a power law

$$
\frac{K}{t_{f}}=\dot{\varepsilon}^{\beta}
$$

between the strain rate and the time-to-failure similar with the relation (1). It should be noted that if $\kappa=\left(\varepsilon_{f}\right.$ $-\varepsilon_{0}$ ), then expression (6) reproduces our empirical relation (1).

Under quasi-static loading experiments, the damage evolution processes in rocks could present some common properties. In three types of experiments, the first stage is either related to the elastic closing of the pre-existing cracks and pores, or to the condition where the crack-closure rate exceeds the

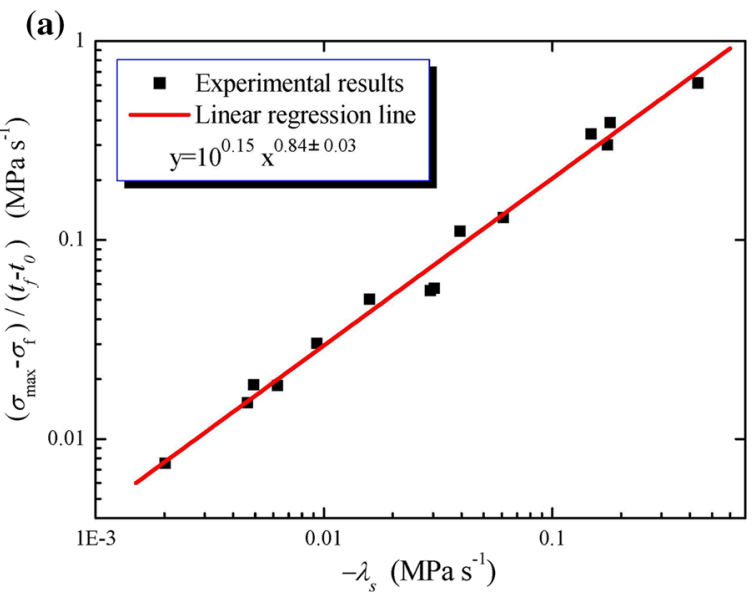

crack-opening and propagation rates (Rudnicki and Rice 1975; Heap et al. 2009; Hao et al. 2013). This leads to an effect of strain hardening in the type 1 (Hao et al. 2013) and type 2 experiments (Lockner and Byerlee 1980; Lockner 1993). The secondary stage corresponds to the stage where damage to rock samples occurs randomly, and thus the spatial distribution of the strain field presents weak fluctuations (Hao et al. 2007, 2010). This occurs so that the macroscopic physical quantities (e.g., average strain or stress) that describe the global average mechanical responses evolve steadily. The diffused distribution of acoustic emission events has also been observed throughout secondary stage in the creep experiments and quasi-constant acoustic emission rate experiments (Lockner et al. 1991; Lockner 1993). The accelerating evolution in the tertiary stage always results from the localization and coalescence of cracks observed in monotonic loading experiments (Hao et al. 2007, 2010), creep experiments, and in quasi-constant acoustic emission rate experiments (Lockner et al. 1991).

To further demonstrate the relationship between failure and the secondary stage, let us focus on the brittle creep relaxation experiments. For a plastic material, stress relaxation is achieved through a process in which the initial imposed elastic strain is replaced over time by an inelastic strain. However, for heterogeneous brittle materials such as rocks, a

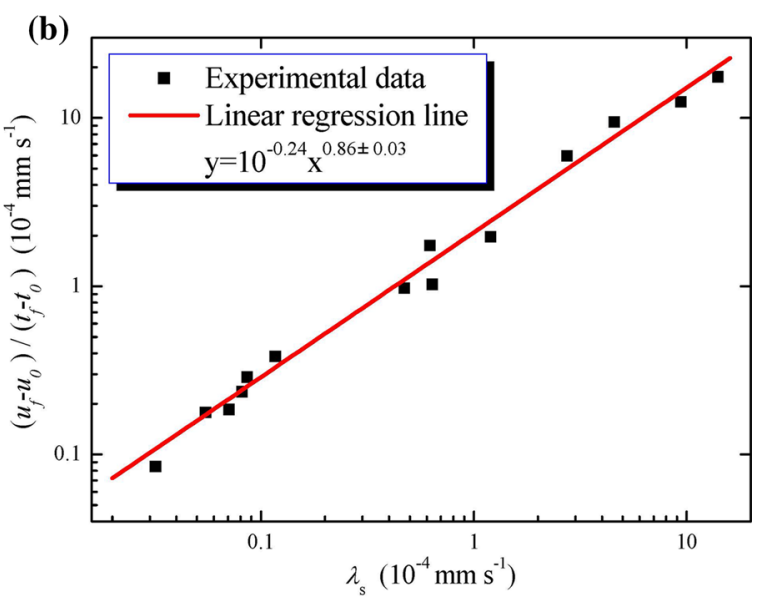

Figure 14

The double-logarithm plots of $\mu$ and $\lambda s$ in brittle creep-relaxation tests. a $\left(\sigma_{\max }-\sigma_{f}\right) /\left(t_{f}-t_{0}\right)$ versus $-\lambda_{s}$ and $\mathbf{b}\left(u_{\mathrm{f}}-u_{0}\right) /\left(t_{f}-t_{0}\right)$ versus $\lambda_{s}$. The data fit well to a power law 
drop in the stress is induced by the development of damage, which includes the initiation, propagation, coalescence, and growth of cracks and defects.

It should be mentioned that the evolution of the macroscopic response depends on the microphysical of the rock specimen, which induces sample-specificities of rock specimens. The evolution properties (e.g., the slope $\lambda_{s}$ of the secondary stage) of the response (strain or stress) curves and the eventual failure are determined by the properties of damage evolution for a specific specimen and the loading condition. In type 1 and type 3 experiments, the elasticity of the testing machine (the stiffness of the loading apparatus is $\sim 130 \mathrm{kN} / \mathrm{mm}$ ) played an extremely important role in promoting failure. The condition of catastrophic rupture in type 1 experiments is controlled by two main factors (Bai et al. 2005; Jeager et al. 2007; Hao et al. 2007, 2010, 2013): the stiffness ratio between the load apparatus and the rock sample, and the damage evolution properties of the rock. The condition of catastrophic rupture in type 3 experiments is controlled by three factors (Hao et al. 2013): the stiffness ratio between the load apparatus and the rock sample, the initial applied displacement, and the damage evolution properties of rock. In the type 2 experiment, failure is determined mainly by the initial stress level and the specific damage evolution properties of a rock specimen. Therefore, it is difficult to decouple these combined effects of loading level, testing machine, and sample-specificities of rock specimens. Both the slope of the secondary stage and failure time are commonly dependent on these conditions. As a result, the variability of these factors do not change the scaling law between the two main macroscopic responses $\left(\lambda_{s}\right.$ and $\mu$ ), but lead to the differences in $\lambda_{s}$, power exponent and failure time among the specimens.

The ratio $\lambda_{s} / \mu$ between the average deformation rate $\lambda_{s}$ of the secondary stage and the average rate $\lambda_{s}$ for whole lifetime reflects the contribution of the secondary stage to the whole failure.

\section{Conclusions}

In the three types of our quasi-static experiments, rock specimens presented an apparent long steady (or pseudo-steady) stage followed by a rapid deformation stage, leading to a macroscopic failure. The steady stage dominates almost the entire lifetime of a rock specimen. A steep slope of the steady stage implies a short lifetime. These properties promise a unified description of the relationship between the time-tofailure and failure with the evolution properties in the steady stage.

The present experimental results show that the lifetime of rock specimens can be commonly expressed as a power-law relationship with the slope of the steady stage [cf. Eqs. (1) and (6)]. The power law exponent is approximately 0.70 in the monotonic loading experiments, $0.92 \pm 0.04$ in the brittle creep experiments, and approximately 0.85 in the brittle creep relaxation experiments. Further investigations are needed to determine the reason for the different exponent values. Under the creep experiments, the approximate linear relationship of the lifetime of rock specimens with a steady stage slope provides a potential method for predicting time-to-failure by using a linear extrapolation.

$\lambda_{s} / \mu$, which is the ratio of the evolution rate in the steady stage with respect to the average rate of the total lifetime, is proposed to describe the failure mode. A larger value of $\lambda_{s} / \mu$ means a smaller damage proportion occurred in the steady stage, and consequently, a larger portion of damage occurred in the tertiary stage, corresponding to more brittle failure.

\section{Acknowledgements}

This work is supported by National Natural Science Foundation of China (Grant 11672258), National Basic Research Program of China (Grant 2013CB834100) and Natural Science Foundation of Hebei Province (Grant D2015203398). We acknowledge useful comments of two anonymous reviewers.

Appendix: results for specimens that failed immediately and did not fail after a long time loading

See Figs. 15 and 16. 

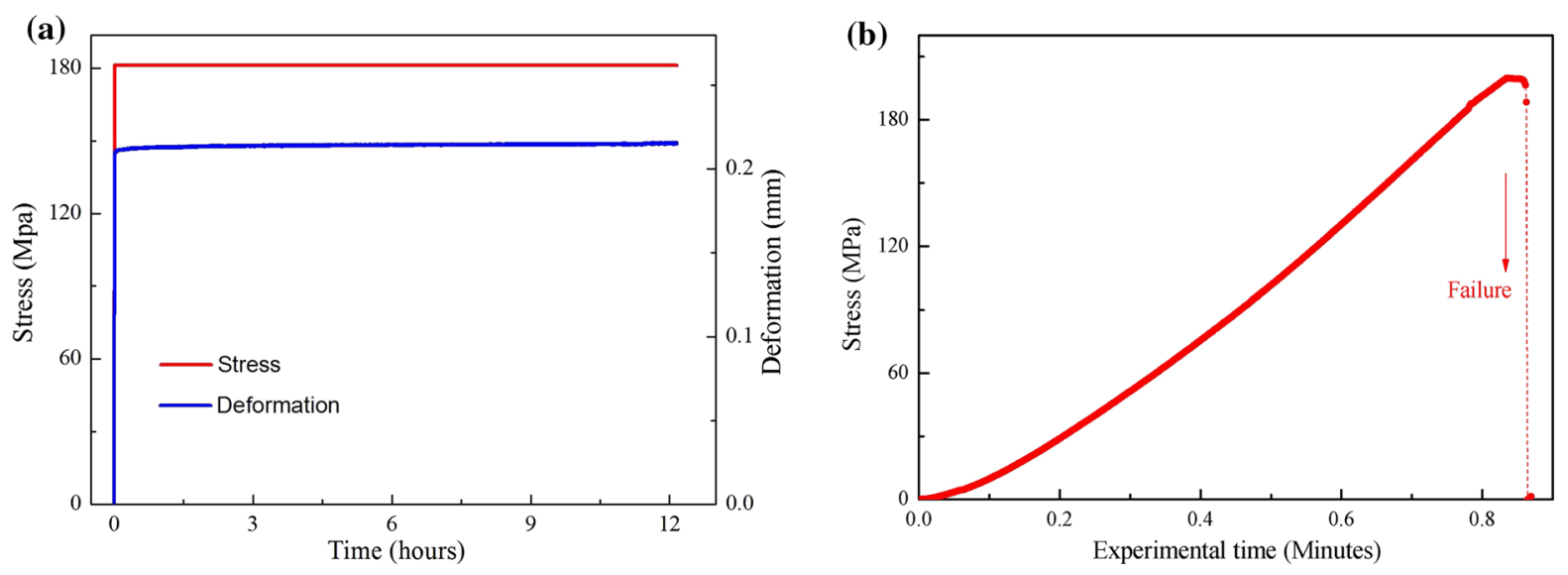

Figure 15

Results of the brittle creep tests: one specimen failed immediately while trying to hold the stress and one did not fail after a long load time. a The results of a specimen that did not fail after a long load time. After approximately $12.16 \mathrm{~h}$ of testing, the data are too large to be stored.

b The curves of stress vs. time of a specimen that failed immediately while trying to hold the stress
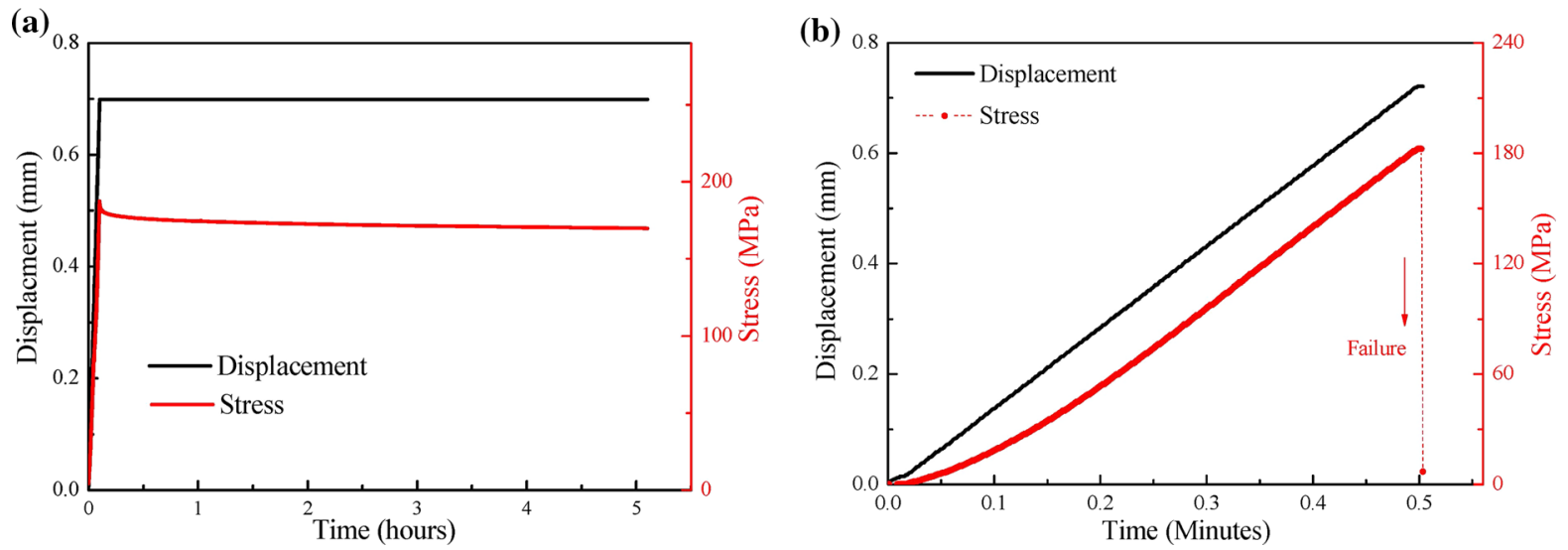

Figure 16

Results in creep relaxation tests: one specimen failed immediately when trying to hold the displacement and one that did not fail after a long time loading. a The results of a specimen that did not fail after a long time loading. After about $5.1 \mathrm{~h}$ in the tests, the data is too large to be stored. b The results of a specimen that failed immediately when try to hold the displacement

\section{REFERENCES}

Amitrano, D., Grasso, J. R., \& Senfaute, G. (2005). Seismic precursory patterns before a cliff collapse and critical point phenomena. Geophysical Research Letters, 32(5), L08314. doi:10.1029/2004GL022270.

Amitrano, D., \& Helmstetter, A. (2006). Brittle creep, damage and time to failure in rocks. Journal of Geophysical Research, 111, 1-17, B11201. doi:10.1029/2005JB004252.

Andrade E. N. da C. (1910). On the viscous flow in metals and allied phenomena. Proceedings of the Royal Society of London. Series A, 84, 1 .
Atkinson, B. K. (1984). Subcritical crack growth in geological materials. Journal of Geophysical Research, 89, 4077-4114.

Atkinson, B., Meredith, P. (1987) The theory of subcritical crack growth with applications to minerals and rocks. In: Fracture mechanics of rocks (pp. 111-166). New York: Academic Press.

Bai, Y. L., Wang, H. Y., Xia, M. F., \& Ke, F. J. (2005). Statistical mesomechanics of solid, liking coupled multiple space and time scales. Applied Mechanics Review, 58, 372-388.

Baud, P., \& Meredith, P. (1997). Damage accumulation during triaxial creep of darley dale sandstone from pore volumetry and acoustic emission. International Journal of Rock Mechanics and Mining Sciences and Geomechanics Abstracts, 34(3-4), 1-8. 
Benioff, H. (1951). Earthquake and rock creep. Bulletin of the Seismological Society of America, 41(1), 31-62.

Boukharov, G., Chanda, M., \& Boukharov, N. (1995). The three processes of brittle crystalline rock creep. International Journal of Rock Mechanics and Mining Sciences and Geomechanics Abstracts, 32(4), 325-335.

Brantut, N., Heap, M. J., Baud, P., \& Meredith, P. G. (2014). Rateand strain-dependent brittle deformation of rocks. Journal of Geophysical Research, 119, 1818-1836. doi:10.1002/ 2013JB010448.

Brantut, N., Heap, M. J., Meredith, P. G., \& Baud, P. (2013). Timedependent cracking and brittle creep in crustal rocks: a review. Journal of Structural Geology, 52, 17-43.

Charles, R. (1958). The static fatigue of glass. Journal of Applied Physics, 29, 1549-1560.

Chen, Z., et al. (2000). Global Positioning System measurements from eastern Tibet and their implications for India/Eurasia intercontinental deformation. Journal of Geophysical Research, 105, 16215-16227.

Cruden, D. (1974). The static fatigue of brittle rock under uniaxial compression. International Journal of Rock Mechanics and Mining Sciences and Geomechanics Abstracts, 11, 67-73.

Das, S., \& Scholz, C. (1981). Theory of time-dependent rupture in the Earth. Journal of Geophysical Research, 86, 6039-6051.

Du, Z. Z., \& McMeeking, R. M. (1995). Creep models for metal matrix composites with long brittle fibers. Journal of the Mechanics and Physics of Solids, 43, 701-726.

Guarino, A., Ciliberto, S., Garcimartin, A., Zei, M., \& Scoretti, R. (2002). Failure time and critical behavior of fracture precursors in heterogeneous materials. European Physical Journal B: Condensed Matter and Complex Systems, 26, 141-151.

Hao, S. W., Liu, C., Lu, C. S., \& Elsworth, D. (2016). A relation to predict the failure of materials and potential application to volcanic eruptions and landslides. Scientific Reports, 6, e27877. doi:10.1038/srep27877.

Hao, S. W., Rong, F., Lu, M. F., Wang, H. Y., Xia, M. F., Ke, F. J., et al. (2013). Power-law singularity as a possible catastrophe warning observed in rock experiments. International Journal of Rock Mechanics and Mining Sciences, 60, 253-262.

Hao, S. W., Wang, H. Y., Xia, M. F., Ke, F. J., \& Bai, Y. L. (2007). Relationship between strain localization and catastrophic failure. Theoretical and Applied Fracture Mechanics, 48, 41-49.

Hao, S. W., Xia, M. F., Ke, F. J., \& Bai, Y. L. (2010). Evolution of localized damage zone in heterogeneous media. International Journal of Damage Mechanics, 19(7), 787-804.

Hao, S. W., Zhang, B. J., Tian, J. F., \& Elsworth, D. (2014). Predicting time-to-failure in rock extrapolated from secondary creep. Journal of Geophysical Research Solid Earth, 119, 1942-1953. doi:10.1002/2013JB010778.

Heap, M. J., Baud, P., Meredith, P. G., Bell, A. F., \& Main, I. G. (2009). Time-dependent brittle creep in Darley Dale sandstone. Journal of Geophysical Research Solid Earth, 114, B07203. doi:10.1029/2008JB006212.

Heap, M. J., Baud, P., Meredith, P. G., Vinciguerra, S., Bell, A. F., \& Main, I. G. (2011). Brittle creep in basalt and its application to time-dependent volcano deformation. Earth and Planetary Science Letters, 37(1-2), 71-82.

Hundson, J. A., Crouch, S. L., \& Fairhurst, C. (1972). Soft, stiff and servo-controlled testing machines: a review with reference to rock failure. Engineering Geology, 6, 155-189.
Jeager, J. C., Cook, N. G. W., \& Zimmerman, R. (2007). Fundamentals of rock mechanics (4th ed.). London: Wiley-Blackwell.

Kilburn, C. R. J. (2012). Precursory deformation and fracture before brittle rock failure and potential application to volcanic unrest. Journal of Geophysical Research, 117, B02211. doi:10. 1029/2011JB008703.

Kranz, R. (1980). The effect of confining pressure and difference stress on static fatigue of granite. Journal of Geophysical Research, 85, 1854-1866.

Kranz, R., Harris, W., \& Carter, N. (1982). Static fatigue of granite at $200^{\circ} \mathrm{C}$. Geophysical Research Letters, 9(1), 1-4.

Labuz, J. F., \& Biolzi, L. (1991). Class I vs class II stability: a demonstration of size effect. International Journal of Rock Mechanics and Mining Sciences and Geomechanics Abstracts, 28(2/3), 199-205.

Lienkaemper, J. J., Galehouse, J. S., \& Simpson, R. W. (1997). Creep response of the Hayward fault to stress changes caused by the Loma Prieta earthquake. Science, 276, 2014-2016.

Lockner, D. A. (1993). The role of acoustic emission in the study of rock fracture. International Journal of Rock Mechanics and Mining Sciences and Geomechanics Abstracts, 30(7), 883-899.

Lockner, D. A. (1998). A generalized law for brittle deformation of westerly granite. Journal of Geophysical Research, 103(B3), 5107-5123.

Lockner, D. A., \& Byerlee, J. D. (1980). Development of fracture planes during creep in granite. In H. R. Hardy, F. W. Leiton, (Eds.) Proceedings of 2 nd conference on acoustic emission/microseismic activity in geological structures and materials (pp 11-25). Clausthal-Zellerfeld, Germany: Trans Tech Publications.

Lockner, D. A., Byerlee, J. D., Kuksenko, V., Ponomarev, A., \& Sidorin, A. (1991). Quasi-static fault growth and shear fracture energy in granite. Nature, 350(7), 39-42.

Main, I. (2000). A damage mechanics model for power-law creep and earthquake aftershock and foreshock sequences. Geophysical Journal International, 142, 151-161.

Meade, B. J. (2007). Present-day kinematics at the India-Asia collision zone. Geology, 35, 81-84.

Nechad, H., Helmstetter, A., Guerjouma, R. E., \& Sornette, D. (2005). Andrade creep and critical time-to-failure laws in heterogeneous materials. Physical Review Letters, 94, 045501.

Okubo, S., Nishimatsu, Y., \& Fukui, K. (1991). Complete creep curves under uniaxial compression. International Journal of Rock Mechanics and Mining Sciences and Geomechanics Abstracts, 28(1), 77-82.

Omori, F. (1894). On the aftershocks of eathquakes. Journal of the College of Science, Imperial University of Tokyo, 7, 111-120.

Perfettin, H., \& Avouac, J. P. (2004). Postseismic relaxation driven by brittle creep: A possible mechanism to reconcile geodetic measurements and the decay rate of aftershocks, application to the Chi-Chi earthquake, Taiwan. Journal of Geophysical Research, 109, B02304. doi:10.1029/2003JB002488.

Petley, D., Bulmer, M., \& Murphy, W. (2002). Patterns of movement in rotational and translational landslides. Geology, 30(8), 719-722.

Rudnicki, J. W., \& Rice, J. R. (1975). Conditions for the localization of deformation in pressure-sensitive dilatant materials. Journal of the Mechanics and Physics of Solids, 23, 371-394.

Saito, M. (1969). Forecasting time of slope failure by tertiary creep. In Proc. 7th Int. Conf. Soil Mechanics and Foundation Engineering, Mexico City (Vol. 2, pp. 677-683). 
Saito, M., Uezawa, H. (1961) Failure of soil due to creep. In Proc. 5th Int. Conf. Soil Mechanics and Foundation Engineering, Montreal (Vol. 1, pp. 315-318).

Salamon, M. D. G. (1970). Stability, instability and design of pillar workings. International Journal of Rock Mechanics and Mining Sciences, 7(6), 613-631.

Scholz, C. (1968). Mechanism of creep in brittle rock. Journal of Geophysical Research, 73(10), 3295-3302.

Scholz, C. (1972). Static fatigue of quartz. Journal of Geophysical Research, 77, 2104-2114.

Shen, Z. K., Lu, J. N., Wang, M., \& Burgmann, R. (2005). Contemporary crustal deformation around the southeast borderland of the Tibetan Plateau. Journal of Geophysical Research, 110, 11409. doi:10.1029/2004JB003421.
Singh, D. P. (1975). A study of creep of rocks. International Journal of Rock Mechanics and Mining Sciences and Geomechanics Abstracts, 12, 271-276.

Utsu, T. (1961). Statistical study on the occurrence of aftershocks. Geophysical Magazine, 30, 521-605.

Voight, B. (1988). A method for prediction of volcanic eruption. Nature, 332, 125-130.

Voight, B. (1989). A relation to describe rate-dependent material failure. Science, 243, 200-203.

Wiederhorn, S. M., \& Bolz, L. H. (1970). Stress corrosion and static fatigue of glass. Journal of the American Ceramic Society, 50, 543-548.

Zhang, P. Z. (2013). Beware of slowly slipping faults. Nature Geoscience, 6, 323-324.

(Received February 1, 2016, revised March 2, 2017, accepted March 10, 2017, Published online March 21, 2017) 